\title{
ОСОБЕННОСТИ ГЛИКЕМИЧЕСКОЙ ВАРИАБЕЛЬНОСТИ У БЕРЕМЕННЫХ ЖЕНЩИН С ГЕСТАЦИОННЫМ САХАРНЫМ ДИАБЕТОМ
}

\author{
Ушанова Ф.О., Измайлова М.Я., Демидова Т.Ю.
}

ФГАОУ ВО Российский Национальный Исследовательский Медицинский Университет имени Н. И. Пирогова, Москва

Ранний контроль гестационного сахарного диабета (ГСД) может снизить вероятность неблагоприятных исходов для матери и плода. Гликемическая вариабельность (ГВ) является более точным параметром оценки риска развития диабетических осложнений, чем традиционные параметры оценки компенсации. В большинстве случаев для лечения ГСД применяется диетотерапия, при этом гликемия у беременной должна соответствовать уровню глюкозы у здоровых беременных. Цель нашей работы сравнить двухнедельные гликемические профили и ВГ беременных с ГСД на диетотерапии и у здоровых беременных с использованием системы флэш-монитора FreeStyle Libre.

МАТЕРИАЛЫ И МЕТОДЫ: анализ гликемического профиля 49 беременных женщин в возрасте $33,2 \pm 6,1$ лет. Средний срок беременности включенных в исследование женщин составил 12,6 6.4 недель гестации. Беременные были распределены на 2 группы: 37 беременных женщин с ГСД и 12 здоровых беременных. По данным дневника самоконтроля с использованием глюкометра все беременные с ГСД имели целевые значения гликемии. В каждой группе проводился двухнедельный мониторинг профиля глюкозы с использованием системы непрерывного мониторирования FreeStyle Libre. Для оценки ВГ были использованы следующие параметры, отражающие различные характеристики гликемической кривой: SD- характеризует степень разброса значений гликемии; MAGE - средняя амплитуда колебаний гликемии; MAG — отражает скорость изменения уровня глюкозы; CONGA - длительность повышения гликемии; $\mathrm{HBGl}$ - индекс риска гипергликемий; LBGI - индекс риска гипогликемий; ADDR - среднее значение рисков. Статистическая обработка данных проводилась с использованием методов параметрического и непараметрического анализа. Систематизация исходной информации и визуализация полученных результатов осуществлялись в электронных таблицах Microsoft Office Excel 2016. Статистический анализ проводился с использованием программ STATISTICA 10 (разработчик — StatSoft.Inc), EasyGV, версия 9.

РЕЗУЛЬТАТЫ: Учитывая особенности контроля при ГСД, были изменены пороговые значения диапазона нормы в соответствии с целевыми значениями для беременных с ГСД. Показатели гликемии и гликемической вариабельности были достоверно выше в группе беременных женщин с ГСД по сравнению с беременными без нарушений углеводного обмена, но в пределах целевого диапазона. Средний уро-

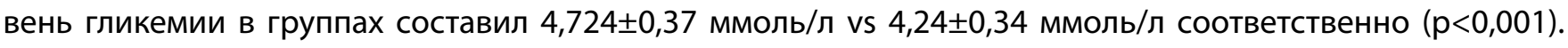
Сравнительный анализ параметров ВГ в группах: SD -0,908 vs 0,7213 ( $p<0,05)$; LI- 1,5 vs 0,8 ( $<<0,05)$; HBGI0,503 vs 0,42 ( $p<0,05$ ); J-index- 10,343 vs 7,9870 ( $p<0,001$ ); MOOD- 0,956 vs 0,7992 ( $p<0,05$ ); MAGE- 2,326 vs $1,8042$ ( $p<0,05$ ); ADDR- 2,216 vs 0,4210 ( $p<0,05)$; MAG- 4,612 vs 2,6163 ( $p<0,001$ ) соответственно. Индекс CONGA не продемонстрировал статистически достоверной разницы в обеих группах: 3,95 vs 3,7 ( $p=0,5)$.

ВЫВодЫ: Flash-мониторирование гликемии может быть использовано для получения более подробной информации о гликемическом профиле, особенно при трудностях в оценке степени компенсации ГСД. Непрерывный мониторинг позволяет более тщательно оценивать эффекты терапии ГСД, в то же время требуются дальнейшие исследования для оценки значимости этих данных. 